\title{
Equilibrium existence in infinite horizon economies
}

\author{
Emma Moreno-García . \\ Juan Pablo Torres-Martínez
}

Received: 31 December 2010 / Accepted: 10 January 2012 / Published online: 21 January 2012 (C) Springer-Verlag 2012

\begin{abstract}
In sequential economies with finite or infinite-lived real assets in positive net supply, we introduce constraints on the amount of borrowing in terms of the market value of physical endowments. We show that, when utility functions are either unbounded and separable in states of nature or separable in commodities, these borrowing constraints not only preclude Ponzi schemes but also induce endogenous Radner bounds on short-sales. Therefore, we obtain existence of equilibrium. Moreover, equilibrium also exists when both assets are numéraire and utility functions are quasilinear in the commodity used as numéraire.
\end{abstract}

Keywords Equilibrium - Infinite horizon incomplete markets · Infinite-lived real assets

This work was partially supported by the research grant ECO2009-14457-C04-01 (Ministerio de Ciencia e Innovación).

E. Moreno-García

Facultad de Economia y Empresa, Universidad de Salamanca, Campus Miguel de Unamuno, 37007 Salamanca, Spain e-mail: emmam@usal.es

J. P. Torres-Martínez

Department of Economics, University of Chile, Diagonal Paraguay 257, Santiago, Chile e-mail: juan.torres@fen.uchile.cl 